\title{
Du même auteur
}

\section{Ouvrages sur les polymères :}

- Mise en forme des polymères. Approche thermomécanique de la plasturgie, avec J.-F. Agassant et J.-Ph. Sergent, B. Vergnes et M. Vincent, Lavoisier, $4^{\mathrm{e}}$ éd. 2014

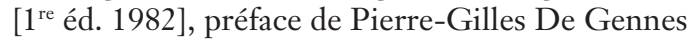

- Polymer processing. Principles and modeling, avec J.-F. Agassant, P.-J. Carreau, B. Vergnes et M. Vincent, Hanser Publishers, $2^{\mathrm{e}}$ éd. 2017 [1 ${ }^{\text {re }}$ éd. 1991]

- "Etymology of main polysaccharide names", Chap. 2 of The European Polysaccharide Network of Excellence (EPNOE), Research initiatives and results, P. Navard (ed.), Springer, 2012

\section{Ouvrages d'étymologie avec Henriette WALTER chez Robert-Laffont :}

- L'Étonnante histoire des noms des mammiferes. De la musaraigne étrusque à la baleine bleue, $2^{\mathrm{e}}$ éd. 2018 [1 ${ }^{\mathrm{re}}$ éd. 2003], republié en 2 volumes « Le goût des mots » chez Points : Chibuahua, zébu et Cie, 2007 et Bonobo, gazelle et Cie, 2008

- La Mystérieuse histoire du nom des oiseaux. Du minuscule roitelet à l'albatros géant, 2007

- La Fabuleuse histoire du nom des poissons. Du tout petit poisson-clown au très grand requin blanc, 2011

- La Majestueuse histoire du nom des arbres. Du modeste noisetier au séquoia géant, 2017

Conception et mise en pages : CB Defretin, Lisieux

Infographie : Minh-Thu Dinh-Audouin

Imprimé en France

ISBN (papier) : 978-2-7598-2302-4 - ISBN (ebook) : 978-2-7598-2303-1

Tous droits de traduction, d'adaptation et de reproduction par tous procédés, réservés pour tous pays. La loi du 11 mars 1957 n'autorisant, aux termes des alinéas 2 et 3 de l'article 41, d'une part, que les « copies ou reproductions strictement réservées à l'usage privé du copiste et non destinés à une utilisation collective », et d'autre part, que les analyses et les courtes citations dans un but d'exemple et d'illustration, « toute représentation intégrale, ou partielle, faite sans le consentement de l'auteur ou de ses ayants droit ou ayants cause est illicite » (alinéa $1^{\text {er }}$ de l'article 40). Cette représentation ou reproduction, par quelque procédé que ce soit, constituerait donc une contrefaçon sanctionnée par les articles 425 et suivants du code pénal. 
Ce n'est point en resserrant la sphère de la nature et en la renfermant dans un cercle étroit qu'on pourra la connaître ; ce n'est point en la faisant agir par des vues particulières qu'on saura la juger ni qu'on pourra la deviner ; ce n'est point en lui prêtant nos idées qu'on approfondira les desseins de son auteur. Au lieu de resserrer les limites de sa puissance, il faudra les reculer, les étendre jusque dans l'immensité ; il ne faut rien voir d'impossible, s'attendre à tout, et supposer que tout ce qui peut être, est.

Buffon, Histoire naturelle 